\title{
PERANCANGAN DAN SIMULASI PUNCH MESIN PRES BATAKO
}

\author{
Muhammad Mishbahul Munir \\ Fakultas Teknik, Program Studi Teknik Mesin \\ Universitas Muria Kudus \\ Email: misbahmunier76@gmail.com \\ Qomaruddin \\ Fakultas Teknik, Program Studi Teknik Mesin \\ Universitas Muria Kudus \\ Email: qomaruddin@umk.ac.id \\ Rochmad Winarso \\ Fakultas Teknik, Program Studi Teknik Mesin \\ Universitas Muria Kudus \\ Email: rochmad.winarso@umk.ac.id
}

\begin{abstract}
ABSTRAK
Batako merupakan salah satu bahan baku bangunan yang paling sering digunakan pada proyek pembangunan properti atau pembuatan rumah biasa, batako biasa digunakan sebagai perkerasan lahan parkir, halaman rumah, dan lain sebagainya, oleh karena itu permintaan pasar akan batako terus bertambah setiap harinya. Metode produksi yang saat ini masih menggunakan cara manual dan proses yang lama mengakibatkan banyak permintaan yang tidak terpenuhi oleh produsen. Oleh Karena itu penulis berupaya membuat mesin pres batako yang hemat dalam proses pembuatan, mudah dioperasikan, dan menghasilkan 10 batako dalam sekali proses. Metode yang digunakan yaitu kajian pustaka, merancang dan simulasi punch. Hasil penelitian adalah desain punch untuk memadatkan 10 adonan batako dalam sekali proses dan menghasilkan gaya $191,1 \mathrm{Nm}$ dalam proses pengepresan.
\end{abstract}

Kata Kunci : Batako, Mesin Pres, Punch.

ABSTRACT

Brick is one of the most used building material in the development property projects or just a simple house build, it's also being used as the floor hardening in a parking lot, a house front yard, and other such things, therefore the market demand of the brick will be increase each day. As these days production methods which are currently still using the manual and long production process will resulting many request cannot be fulfilled by the brick manufacturer. Therefore the writer are making an efforts to create a low cost brick pressing machine, easy to operate, and can produce ten bricks in one time process. The method is designing the punch that are going to be use to solidify ten bricks mixing. The results of research was punh design with 10 time process and result a 191,1 Nm force in the pressing process.

Keywords : Brick, Press Machine, Punch.

\section{PENDAhULUAN}

Batako adalah salah satu bahan baku bangunan yang sangat dibutuhkan untuk kebutuhan properti bangunan seperti gedung, rumah, lahan parkir, halaman rumah, dan lain sebagainya, oleh 
karena itu banyak sekali permintaan batako dari konsumen, padahal banyak sekali pengrajin batako di daerah yang masih menggunakan metode percetakan manual yaitu dengan memasukan adonan ke dalam cetakan dan ditekan - tekan sampai rata kemudian didorong untuk mengeluarkan batako dari cetakan [1].

Di Desa Berantak Sekarjati 04/05 Welahan Jepara, tepatnya di TB Al-Barkah pengrajin batako masih menggunakan sistem produksi manual yang hanya menggunakan satu cetakan dan banyak memakan waktu pada saat pembuatan batako hanya bermodalkan tenaga manusia dengan cara di tekan pada adonan berkali - kali guna untuk memadatkan adonan batako tersebut [2].

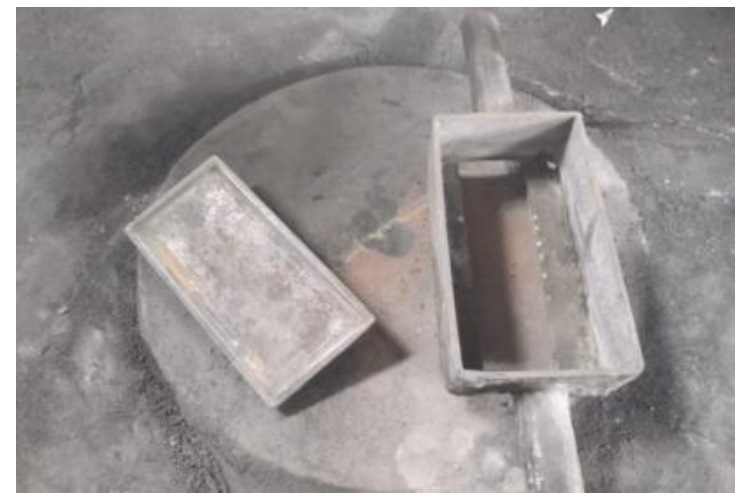

Gambar 1. Cetakan Batako Manual

Perkembangan teknologi seperti sekarang ini model cetakan seperti ini bisa dibilang ketinggalan zaman karena metodenya yang masih menggunakan cara manual dan banyak memakan waktu, dari hasil survei saya di TB Al-Barkah batako yang dihasilkan dari cetakan seperti ini adalah 300 - 400 batako per hari, itu juga dilakukan oleh operator atau tukang yang sudah berpengalaman [3].

Pada perencanaan Punch mesin pres batako 10 biji sekali cetak yang diharapkan mampu menghasilkan minimal 1000 batako per hari dan bisa membantu mempercepat produksi batako untuk memenuhi permintaan pasar. Gerakan punch dapat dilakukan analisa dengan metode pemodelan dan simulasi [4].

\section{METODOLOGI PENELITIAN}

Metode penelitian meliputi kegiatan studi pustaka, desain punch, perhitungan punch dan simulasi. Perhitungan punch meliputi kegiatan sebagai berikut :

\subsection{Perhitungan Gaya Yang Dibutuhkan Untuk Mengepres Batako}

- Gaya yang dibutuhkan Untuk Mengepres Batako

Perhitungan gaya yang dibutuhkan untuk mengepres batako diambil dari Dies ditunjukkan persamaan 1.:

$\mathrm{F}=\mathrm{K} \cdot \mathrm{T} \cdot \sigma B$

(1)

Dimana :

$\mathrm{K}=$ Keliling $(\mathrm{mm})$

$\mathrm{T}=$ Tinggi $(\mathrm{mm})$

$\sigma B=$ Tegangan tarik $\mathrm{N} / \mathrm{m}^{2}$

$\mathrm{F}=$ gaya $(\mathrm{N})$ 


\subsection{Gaya Yang Dihasilkan Punch}

Untuk memadatkan adonan batako dibutuhkan gaya yang dihasilkan dari Punch yang digerakan oleh operator, gaya tersebut bisa digambarkan dengan persamaan 2 sebagai berikut :

$\mathrm{W}=\mathrm{m} \cdot \mathrm{g} \cdot \mathrm{h}$

(2)

Dimana :

$\mathrm{W} \quad=$ usaha $(\mathrm{J})$

$\mathrm{m} \quad=\operatorname{massa}(\mathrm{kg})$

g $\quad=$ gravitasi $\left(\mathrm{m} / \mathrm{s}^{2}\right)$

$\mathrm{h} \quad=$ ketingian $(\mathrm{m})$

\subsection{Kekuatan Baut Pada Punch}

Plat di sambung menggunakan baut dan baut M12 diambil dari ukuran baut dan mur diambil dari ukuran baut dan mur $(10,106)$ yang mengikat pada Punch dan Punch Holder. Pembautan akan terjadi tekanan pada poros karena tekan yang dilakukan oleh Punch maka baut akan terkena beban aksial dan mengakibatkan tegangan geser dari baut.

Tegangan Geser Baut menggunakan persamaan 3.

$$
\tau_{\mathrm{b}}=\frac{w}{\pi \cdot d_{1} k p \cdot z}
$$

$$
\begin{array}{ll}
\text { dimana : } \\
\tau_{\mathrm{b}} \quad \text { = tegangan izin geser, }\left(\mathrm{kg} / \mathrm{mm}^{2}\right) \\
\sigma \mathrm{t} & =\text { Tegangan tarik maksimum bahan }(\mathrm{N} / \mathrm{mm} 2) \\
\mathrm{W} & =\text { beban tarik aksial pada baut, } \mathrm{kg} \\
\mathrm{kp} & =\text { tebal akar ulir luar/baut, mm } \\
\mathrm{Z} & =\text { Jumlah ulir mur yang diperlukan, } \mathrm{mm} \\
\mathrm{d}_{1} & =\text { diameter dalam, mm }
\end{array}
$$

\subsection{Perhitungan Kekuatan Las Pada Punch}

Untuk seberapa seberapa kuat beban yang dapat di terima oleh plat maka perhitungan pengelasan dengan lebar plat $150 \mathrm{~mm}$ dan tebal $6,5 \mathrm{~mm}$ tegangan tarik las smaw Elektroda E7016 dengan arus ampere $150 \mathrm{~A} \sigma=4,70 \mathrm{Mpa}$ dengan menggunakan pengelasan double paralel fillet dan single paralel fillet maka di dapat persamaan 4 [5] :

Kekuatan geser maksimum sambungan las double paralel fillet

$$
\mathrm{F}=\frac{\mathrm{t} \times \mathrm{l}}{\sqrt{2}} \times \tau=1,414 \times \mathrm{t} \times \mathrm{L} \times \tau
$$

(4)

$$
\begin{array}{ll}
\text { dimana : } & \\
\mathrm{F} & =\text { gaya, } \mathrm{N} / \mathrm{mm}^{2} \\
\sigma_{\mathrm{t}} & =\text { tegangan tarik ijin bahan las } \\
\tau & =\text { tegangan geser ijin bahan las } \\
\mathrm{p} & =\text { tebal, } \mathrm{mm} \\
\mathrm{L} & =\text { lebar, } \mathrm{mm}
\end{array}
$$

\subsection{Simulasi}

Perancangan Punch menggunakan Software Autodesk Inventor Profesional 2015 dan dengan menggunakan beberapa metode untuk mengetahui spesifikasi dari Punch yang dibuat. 


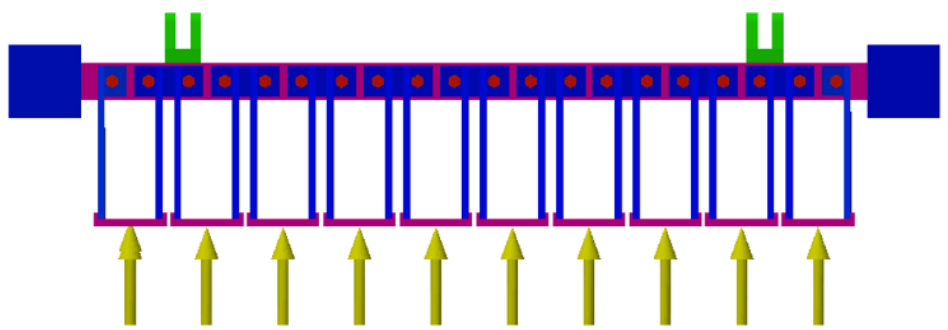

Gambar 2. Pembebanan Pada Punch. ( Sofware Autodeks Inventor 2015 )

Pada gambar 2 diatas merupakan hasil dari pembebanan pada Puch yaitu Displacement anak panah warna kuning adalah arah gaya pembebanan yang telah ditentukan.

\section{HASIL DAN PEMBAHASAN}

\subsection{Hasil Simulasi Software Sofware Autodeks Inventor 2015}

Pada simulasi Punch menggunakan Sofware Autodeks Inventor 2015 gaya yang diberikan pada simulasi 0,003 psi. Ada dua komponen yang diuji yaitu plat Punch dan penyangga Punch. Dan juga ada beberapa hasil yaitu Displacement dan Von Mises Stress.

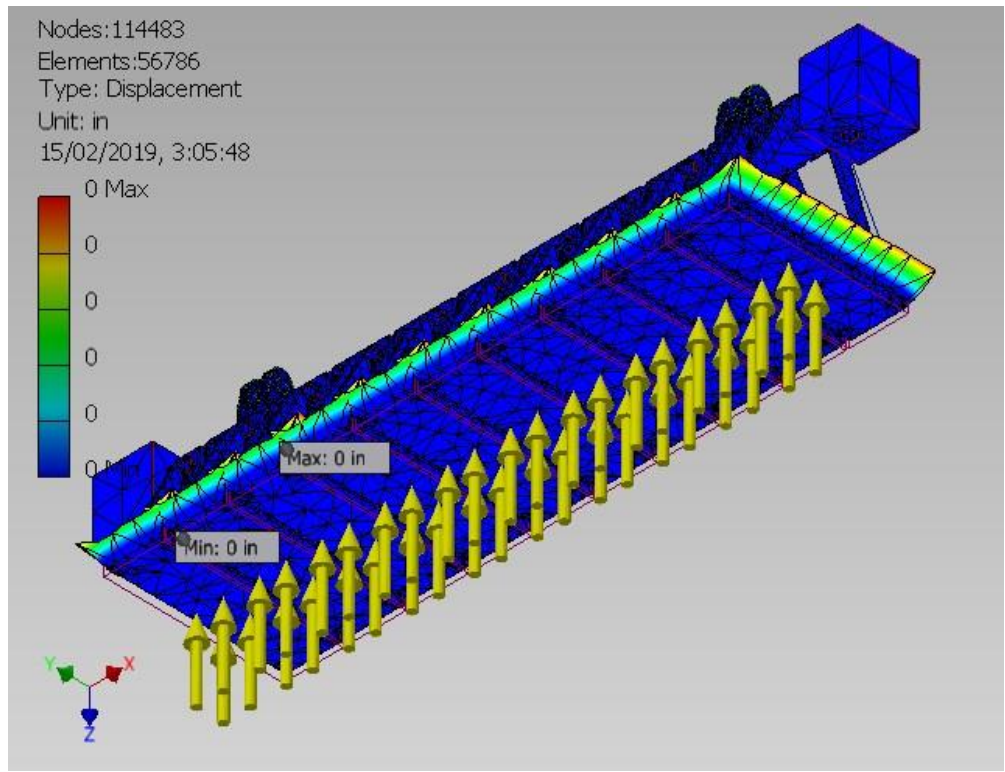

Gambar 3. Displacement Punch (Software Autodesk Inventor Profesional 2015)

Pengujian menggunakan Software Autodesk Inventor Profesional 2015 dengan besar tekanan 0.003 psi dan menghasilkan Displacement 0 in ditunjukkan gambar 3. 


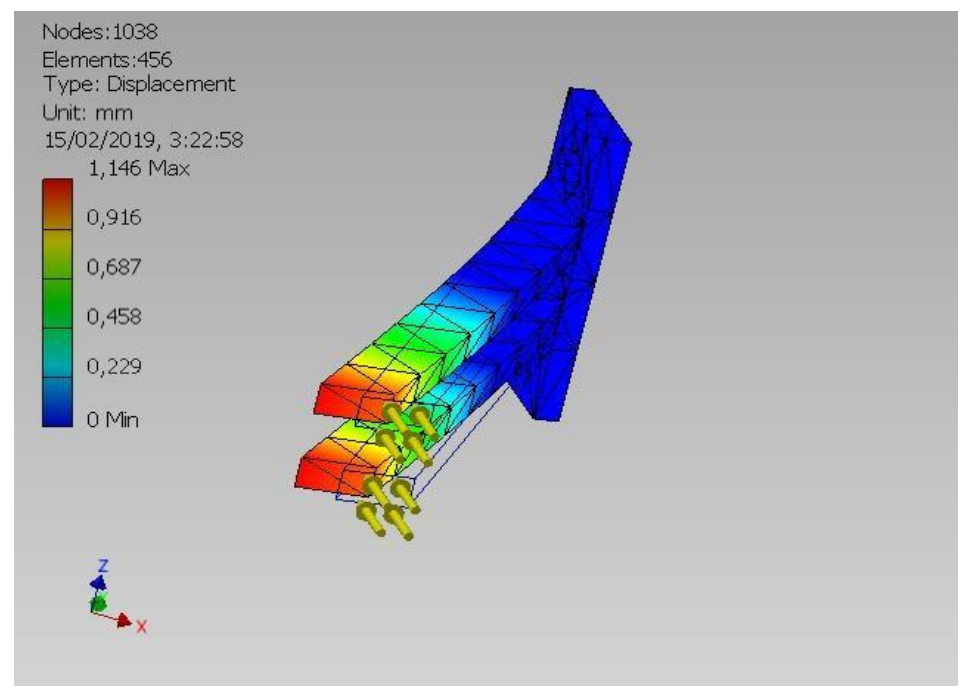

Gambar 4. Pengujian Penyangga Punch (Software Autodesk Inventor Profesional 2015)

Pengujian menggunakan Software Autodesk Inventor Profesional 2015 pada penyangga Punch dengan tekanan sebesar $4.775 \mathrm{Mpa}$ dan Displacement yang dihasilkan 1,146 mm ditunjukkan pada gambar 4.

Dari hasil diatas bisa disimpulkan bahwa komponen yang palling banyak menerima beban adalah penyangga Punch.

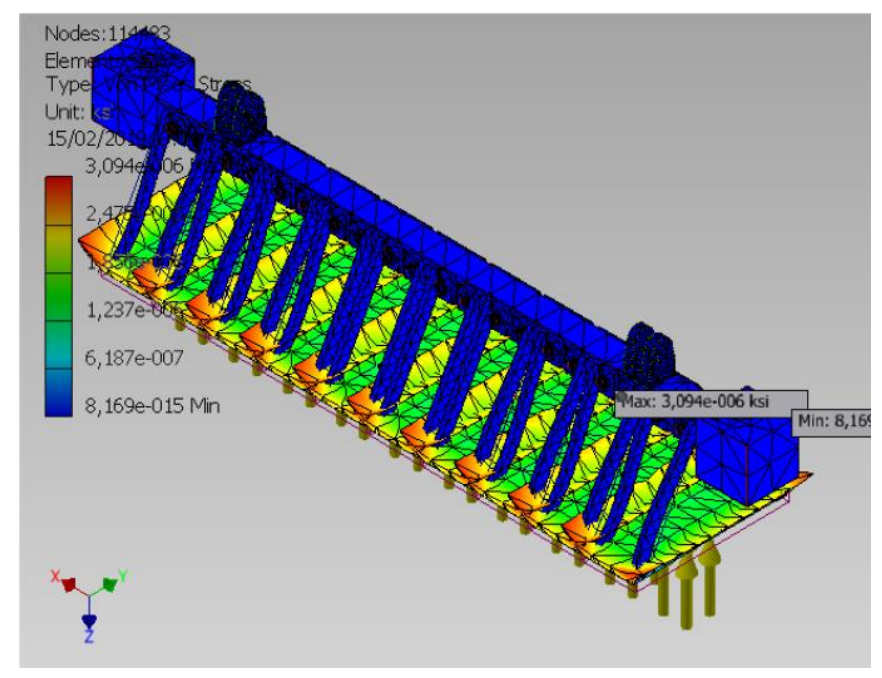

Gambar 3.3. Von Mises Stress Punch (Software Autodesk Inventor Profesional 2015)

Pengujian menggunakan Software Autodesk Inventor Profesional 2015 dengan besar tekanan 0.003 psi menghasilkan Von Mises Stress sebesar 3,094 ksi.

Dari hasil pengujian diatas diperoleh data sebagai berikut:

1. Displacement pada Punch sebesar : 0 in

2. Displacement pada penyangga Punch sebesar $\quad: 1,146 \mathrm{~mm}$

3. Von Mises Stress Pada Punch sebesar : :3,094 ksi 


\section{KESIMPULAN}

Dari rancang bangun Punch mesin pres batako dengan simulasi menggunakan Software Autodesk Inventor Profesional 2015 dapat disimpulkan sebagai berikut:

1. Dari desain Punch mesin pres batako yang sudah dibuat proses pencetakan batako bisa lebih cepat yaitu 10 batako dalam sekali proses.

2. Proses pencetakan batako yang sederhana yaitu dengan mengisikan adonan batako kedalam Dies kemudian mengungkit Punch dan menmenjatuhkannya beberapa kali dan kemudian mengangkat Dies untuk mengeluarkan batako dari cetakan atau Dies.

3. Dari hasil simulasi yang diperoleh dari Software Autodesk Inventor Profesional 2015 bisa disimpulkan bahwa Punch yang dibuat aman untuk produksi sehari - hari.

\section{DAFTAR PUSTAKA}

[1] Setiawan, 2012. Rancang Bangun Punch dan Dies Pada Mesin Pres Batako Styrofoam dan Botol Plastik. Program Diploma III Teknik Mesin Produksi Jurusan Teknik Mesin Fakultas Teknik Universitas Sebelas Maret Surakarta.

[2] Hilman / 20405140. Perancangan dan Analisis Stamping Dies untuk Pembuatan Produk Bracket Bumper Dengan Proses Pres Multi Forging. Fakultas Teknologi Industri, Jurusan Teknik Mesin Universitas Gunadarma Jl. Margonda Raya No.100, Depok 16424 E-mail : azmi_nighmare@yahoo.co.id.

[3] Dharma, Lukito Dwiyuono 2016. Analisa Pengepresan Dengan Sistem Hydrolik Pada Alat Pembuat Paving Block Untuk Perkerasan Lahan Parkir. Program Studi Teknik Mesin Fakultas Teknik Universitas Muhammadiyah Metro J1 Ki Hajar Dewantara 15 A Metro Lampung.

[4] M Kabib, L Batan, I Made, B Pramujat, A Sigit Pramono. 2015 Analisa dan simulasi gerak Aktuator Punch pada Mesin Pres untuk Proses Deep Drawing, Proseding Seminar Nasional Tahunan Teknik Mesin XIV (SNTTM XIV) 15 (UNLAM), 6

[5] Atmaja Mukti1), Rudy Poeng2), Tertius V. Ulaan3). Perbandingan kekuatan pengelasan listrik dengan pengelasan gas pada material besi siku jis g3101. Jurusan Teknik Mesin Universitas Sam Ratulangi. 